\title{
CONNECTING MULTIPLE INTELLIGENCES THROUGH OPEN AND DISTANCE LEARNING: GOING TOWARDS A COLLECTIVE INTELLIGENCE?
}

\author{
Leandro Mauricio Medeiros Vieira [eandro@administradores.com.br], Administradores Digital Business \\ Website, Joao Pessoa, Brazil \\ MarcosFerasso[admmarcos@admmarcos.adm.br],Federal University of Technology of Parana, Curitiba, Brazil \\ Christine da Silva Schröeder [christine@unisc.br], Santa Cruz do Sul University, Santa Cruz do Sul, Brazil
}

\begin{abstract}
This theoretical essay is a learning approach reflexion on Howard Gardner's Theory of Multiple Intelligences and the possibilities provided by the education model known as open and distance learning. Open and distance learning can revolutionize traditional pedagogical practice, meeting the needs of those who have different forms of cognitive understanding. This tool has in itself the potential to build knowledge collectively. The conclusions raise new questions for future discussion, shedding some light on the open and distance learning not as a mere tool to spread education, but as a means to reach new levels of comprehension and consciousness, reflecting on the role of education itself.
\end{abstract}

Keywords: Distance learning; multiple intelligences; knowledge; open learning; pedagogical practices; cognitive understanding.

\section{Introduction}

The awakening of humanity shall be a collective process or nothing at all. The same light goes through all droplets (Pierre Lévy).

This essay was inspired by Howard Gardner's Theory of Multiple Intelligences and the possibilities offered by the education model known as open and distance learning.

The traditional education system is still strongly linked to the idea that there is only one type of intelligence, which can be measured through IQ or similar tests. The advent of new digital technologies - especially internet tools that allow human interaction in 'cyberspace' (the word will be defined later) - has greatly improved the distance learning model. Through the open and distance learning it is possible to revolutionize the traditional pedagogical practices, thus meeting the needs of those who have different forms of cognitive understanding.

Castells (2000) predicts that the future of education lies in the combination of online distance learning and face-to-face learning. The operation will take place "among computer nets, classrooms and the place where each student is."

In this research, open and distance learning is considered as an approach to learning focused on seminal works of Keegan (1993), Holmberg $(1995,2005)$, and Peters $(1992,2002)$, a space where 
learners can overcome limitations of physical distance and time to learn using flexible learning opportunities from whatever those opportunities are. A space where learners can interact with others in a new and wide way, in a flexible way, where decision in what to read, write or comment is on learner supported by an educator that facilitates learning in this new approach. Learners can apply a desirable course from an institution of another country due to particular factors of choice, and can learn combining time and place, balancing work tasks, family responsibilities and new opportunities to improve his/her knowledge level. Open and distance learning refers to the democratised access to learning, where it can be perceived policies and open admissions, freedom to select what, when and by which way to learn. This approach of learning requires a new organizational structure, new forms of communication among learners and educators and a vast and modern set of technologies to support these new ways of learning that go beyond the traditional classes from academia (Keegan, 1993; Holmberg, 1995, 2005; Peters, 1998, 2002; UNESCO, 2012). So, we agree with Rowntree (1992) approach that open and distance learning are complementary ways and can be useful tools to improve learning in this new 'hybrid' way.

The consequences of the changes under way are still open to discussion and thinking. This research, with a learning approach, will show some possibilities that arise from the interconnection of multiple intelligences through the open and distance learning. It is an effort to identify possible escape routes, alternative ways that may surpass the ordinary education tools.

\section{Pluralizing Intelligence}

For a long time, the concept of intelligence was characterized by a single pattern: people were believed to be born with a certain amount of intelligence; this amount could hardly be altered due to its genetic character; and being measurable this intelligence could be measured through IQ tests or similar instruments. In the late 1970s and early 1980s, Howard Gardner, a groundbreaking psychologist and researcher from Harvard University, put an end to this notion, developing a new perspective, which he called "theory of multiple intelligences".

Gardner's conclusions are based on evidences from anthropology and human mind studies. Through a multidisciplinary investigation, he reached the following definition for intelligence: intelligence is "a biopsychological potential to process information that can be activated in a cultural setting to solve problems or create products that are of value in a culture" (Gardner, 2001). These diverse capacities to process information were defined by Gardner (2006) as "intelligences", in the plural. According to Gardner, there are at least seven types of intelligences, which are as follows:

1. Linguistic intelligence involves sensitivity to spoken and written language, and lies on the auditory-oral level, related to the capacity to create stories, and the use of language to reach certain objectives.

2. Logical-mathematical intelligence shows one's capacity to analyze problems logically, do mathematical calculations and computations, and find one's way around numbers.

3. Musical intelligence involves a special skill in performance, composition and appreciation of music and musical qualities.

4. Spatial intelligence deals with the capacity to recognize and manipulate space patterns and to create spatial depictions or images mentally.

5. Bodily-kinaesthetic intelligence deals with the capacity, or potential, to solve problems or create products using parts of the body, such as the hands or the mouth.

6. Interpersonal intelligence is the capacity to understand other peoples' intentions, motivations and desires, thus being able to effectively work with others. 
7. Intrapersonal intelligence along with intrapersonal intelligence, deals with oneself, one's inner side. It is the capacity to know oneself, to identify one's feelings, goals, fears, and personal strengths and weaknesses, and, at the same time, to have control over one's emotions and oneself.

These seven types of intelligence were listed in the first edition of the 1983 book Frames of Mind: The Theory of Multiple Intelligences. Later, Gardner also observed the existence of an eighth intelligence - naturalist intelligence - that implies the capacity to discern the natural world, by demonstrating expertise in classification of numerous species in the environment. He also considered the possibility of two further types of intelligence, still subject to confirmation. These would be the spiritual and existential intelligences.

Gardner (2001) states, that each person has a unique mix of intelligences. The great challenge put to mankind is to find out how "to take advantage of the uniqueness conferred on us as a species exbibiting several intelligences."

\section{Changing Environment and the Rebirth of Distant Learning}

Spanish sociologist Manuel Castells, in his book End of the Millennium (1998), which is the third volume of his trilogy The Age of Information: Economy, Society and Culture, states that the technological revolution based on information has been the catalyzing element of a series of changes that have affected several aspects of society, especially since the last two decades of the twentieth century: "the way we think, produce, consume, negotiate, manage, communicate, live, die, make war and make love."

That is the general trend toward 'virtualization' movement, identified by Lévy (1998), which now affects communication, information, economy, collective sensitivity, and even the use of intelligence. It also affects aspects such as being together, the construction of "we" - for instance, 'virtual' organizations, virtual communities, 'virtual' democracy, and even virtual relationships. Virtualization is a background force that greatly surpasses computer technology: we are talking about real social transformations. In Deleuze's words (1995), "Virtual has its full reality, while virtual'.

While we watch these transformations, we observe a grave crisis in our traditional education system, still stuck in a pattern of delivering knowledge on a teacher-student basis. Although the theory of multiple intelligences is over twenty years old, most schools and universities still apply the paradigm of a single intelligence pattern. The linguistic and logical-mathematical intelligences are typically valued in this system, normally based on expository classes, lectures, writing and calculations. Gardner (2001) states that any uniform pedagogical approach will only work with a small percentage of students. Once we are aware that people are extremely different in the way they acquire and display knowledge, the big challenge for education is; therefore, to make these differences the core of teaching and learning. Otherwise, the education system will keep meeting only the needs of the elite, especially those who learn a certain way, in general, the linguistic or logical-mathematical.

According to Nogueira (2003), education is going through an orientation crisis, a crisis of complexity. Education is faced with the challenge of responding to the needs of children, the youth and adults who "live in a world characterized by highly praised transformations, losing orientation and certainties, and by the lack of references, but which at the same time is full of possibilities and creations." 
In fact, there is a parallel movement which, though faint, seems to be an 'escape route', a new direction for educational practice. One of the revolutions in education, which represents a great potential to serve the several types of intelligences postulated by Gardner, is presented to us as open and distance learning.

Gardner (2006) says that even sudden changes generally mask subtle processes, which in time are consolidated. Unlike the common thought that distance learning is something new, resulting from recent internet-related technology, it is actually an old practice that goes back to Plato's letters to his disciples and Saint Paul's epistles to the first Christian communities.

According to Peters $(2002,2004)$, after the first unique attempts in ancient times, there was an "unexpected and surprising" spread of the 'correspondence education' in the mid-nineteenth century. At that time, several correspondence schools appeared in countries such as England, France and Germany, which offered instruction to people who had been cast aside by the education system and to those who lived far from their native countries, in the colonies.

Peters $(2002$, 2004) presents historical landmarks for the development of this form of learning: the industrialization of distance education caused three fundamental structural changes - new pedagogical concepts and their implementation, advanced educational technology (especially print, multimedia and networked computers); and new institutional settings attracting new types of students and elicited new teaching and learning behaviour.

In the 1970s, open and distance learning model received a new push from "distance-learning universities". The founding of the British Open University in 1969 marks the beginning of a period in which degree-giving distance-teaching universities with full degree programmes confer prestige on distance education (Holmberg, 1995). This phase can be characterized by the additional use of two means of communication: radio and television. Later, the VCR and video tapes were also applied as open and distance learning's tools. Now we have finally reached the online phase of education and learning - made possible through new digital communication formats -, and the means to interact in virtual learning environments in cyberspace (Peters, 2002, 2004) and largely discussed by Anderson and Elloumi (2004), stressing the implementation aspects of online education (infrastructure, content development, design and development of online courses, quality control, and student support).

According to Lévy (2001[a]; 2001[b]), cyberspace, also known as "net", is the "new communication medium which resulted from the world-wide interconnection of computers (internet). The term designates not only the hardware infrastructure of digital-controlled communication, but also the ocean-like universe of information that it contains, as well as the human beings who swim in it and feed it." According to Lemos (2002), cyberspace is an environment where pluralistic discussions take place, which emphasizes diverse skills and takes advantage of the knowledge incited by the formation of community links, which can potentialize the exchange of skills, and create collective knowledge.

Particularly after the most recent phase of the open and distance learning, this subject has been drawing the attention of diverse professionals, from sociologists, philosophers, psychologists and educators to managers and entrepreneurs. This subject attracted this attention also due to the evolution of Information Society that required a new form of learning (Nyíri, 1997). The former were probably interested in the transformations and consequences that the "new" educational model could bring to people and society. The latter were undoubtedly interested in the open and distance learning advantages and the new types of markets and businesses that arise from exploring new educational practices. Peters $(2002,2004)$ underlined this phase as a 'transition 
moment' on their seminal works, also reinforced by Palloff and Pratt (2007). According to these authors, academic institutions are more and increasingly engaged in using the internet to teach distance courses and increase the number of educational programs offered in their campuses. We need to underline the contribution of Cardoso and Bidarra (2007) when argue that technology is, at the same way, the solution and the problem, what affects open and distance learning.

Bayma (2004) points out to the need to explore all possibilities arising from distance-learning technology. Open and distance learning should not be a reproduction of traditional classes. Bayma compares this (scarcely creative) practice to the early days of movie-making, when films were merely a copy of theatre (on-stage shooting), which showed the fear of change. "It is fundamental to explain the advantages of the tools, and to reinforce the potentiality of this media to go beyond traditional classes."

Therefore, one can say that the open and distance learning is a process that emphasizes (or should emphasize) the construction and socialization of knowledge (Schlemmer, 2005). Unlike the situation in the traditional education system, in distance learning, the teacher who passes on contents is replaced by a new type of educator. Lévy (2001a) calls this new teacher the "animator of the collective intelligence", of groups that are under his/her responsibility. Lévy's work supports the idea that teachers' efforts should serve to stimulate learning and thinking. Their activity should focus on assisting and managing learning: "inspiring the exchange of knowledge, the relational and symbolical mediation, the individual control of learning paths, etc."

Palloff and Pratt (2007) follow that same reasoning, establishing the end of the unidirectional communication of knowledge. They acknowledge the fact that learning should consist of an interaction among students, between teachers and students, and of the learning collaboration which results from these interactions. Nogueira (2003) postulates that in virtual learning environments, all concepts and theories are interconnected and have no hierarchies. That implies a system open to participation, capable of generating ongoing growth and transformations.

Gardner (2001) also shows great enthusiasm regarding the several windows of opportunity created by new digital tools. For Gardner, such technologies create the possibility of a "quantum leap" in customized services rendered to students and teachers. Nowadays, it is already possible to design computer programs for the different intelligences, allowing students to show their comprehension in several systems of symbols - linguistic, numerical, musical, graphical, etc., in addition to allowing teachers to check students' work in a more flexible and faster way. Gardner (2001) emphasizes the use of email, websites, videoconferences among other tools largely used in distance learning. He also takes into consideration the development of "intelligent systems". $\mathrm{He}$ says that "these systems are capable of modifying exercises as well as the pedagogical return based on previous success or failure. (...) Current technologies seem tailor-made to belp bring into reality the kind of MI (multiple intelligences) approach I have endorsed."

Farquhar (2013) highlighted the way communication occurs - in the sense of efficiency and quality of this communication. This is what Moore (1993, as cited in Farquhar, 2013) referred to as transactional distance: when dialogue is high, the transactional distance is understood to be low. And more: "Collaborative learning is built on a variety of communicative modes in which dialogue is key."

So, the open and distance learning model is a good answer to potentiate and extend the ways in which a learner can learn, using the gardnerian's approach of 'intelligences', and that an open and distance learning can explore at all. Its goal will not be reproducing the classic classes, the classic learning way: open and distance learning can be a learning tool like a kaleidoscope of possibilities 
that allow group members acquire new knowledge in a broader way, using unused 'intelligences', unused ways of learning, unused learning tools, unused creation possibilities by learners.

\section{Multiple Intelligences in Connection: a Community Culture}

It is clear that the open and distance learning enthusiasts' proposition is to remove the distance between teachers and students, and put all actors in touch so they can share their individual knowledge, wisdom and intelligences. Philosopher Pierre Lévy is one of the main scholars who support this teaching and learning method. His book Cyberculture (2001a) proposes the following.

Instead of pyramids built in levels, organized according to prerequisites and converging to a "superior" wisdom, we should choose the image of a space for emerging, open, continuous, flowing, non-linear knowledge, which is organized according to its goal and context, where each item fills a unique and evolving position.

It so happens that the principles involved in distance learning are those attributed to a more active and collaborative form of learning, but with a difference: it is important to pay attention to the development of a community feeling among participants. This is one of the main factors for the success of the process (Palloff \& Pratt, 2007). "The community is the vehicle through which learning occurs online". Schlemmer (2005) describes virtual community as a somewhat permanent collectiveness, which depends on its members' interests, and organized by tools offered in cyberspace. According to Schlemmer, these communities feed on the flow of interaction, and on deterritorialized, transversal, free human relations.

The concept of community is broadly defined in areas like Sociology, Psychology, and Anthropology, to cite the most cited fields of studies. In this research, the most adequate concept of community came from Psychology, where McMillan and Chavis (1986) propose a set of four elements that form the 'sense of community': 1) membership, 2) influence, 3) integration and fulfilment of needs, and 4) sharing of emotional connections. This concept is based on the fact that people have a necessity to being part of a group, with a perceived influence over other groups of individuals, fulfilment of their needs of integration, common values, and gains (material or non-material) that come from the group to its members. So, the concept of community congregates a group of individuals that have a sense of membership and join to gain something from this membership.

In such way, a community (or a group, in this case) is composed by its members that, individually, have knowledge, learning needs and intelligence (in the sense of Gardner's approach) and this community or group is formed by the sense of being part of a group that want to gain something value by its members, a common gain that can be translated as new knowledge, acquired by gardnerian's 'intelligences', which is supported by the open and distance learning way of learning. Traditional classes cannot give the proper answer to this kind of learning model due the vast way people can learn in the gardnerian's approach of 'intelligences' and also due to the vast possibilities made available by the open learning (which implies that the learner chose what will fulfil his/her learning and knowledge needs) and by the distance learning that allow different kind of learning opportunities, mainly due to the evolution and applicability of information technology to education field (i.e., by the introduction of internet, new and digital learning tools, and interaction tools).

Lévy (2001a; 2001b) states that the development of virtual communities is based on interconnection. They arise from common interests, knowledge and mutual projects, in a process of cooperation or exchange, regardless of geographical distances and institutional affiliations. 
When it comes to distance learning, communities built around the objectives of their members are known as learning communities. We need to consider the concept of 'Community of Inquiry' (CoI), underlined by Akyol et al. (2009) as a prominent model of teaching and learning. Rourke and Kanuka (2009) revealed that "[...] students believe that they learn a lot in CoI, but the type of learning is lower-level, [...] Respondents believe that the processes and activities through which they gain this knowledge is didactic instruction and independent work."

Palloff and Pratt (2007) state, that what distinguishes distance learning is the formation of a community of that sort - and not only of a (virtual) social community. While the latter is formed around diverse goals, a learning community is based on incentive and support for knowledge acquisition. There is a general incentive towards group learning, renewing the passion for discovering new worlds of education. "Collaboration, which results from group learning, creates a feeling of synergy (...). The resulting knowledge thus acquired and shared is a lot bigger than the one that might be created when studying through individual and independent means." Lévy (2001a) points out, that teachers can profit from this process too: they learn along with the students and constantly update their knowledge and their pedagogical skills.

The result of a social production and knowledge acquisition can be named collective intelligence. Malone, Laubacher and Dellarocas (2010) state, that collective intelligence is not new. Families, countries, armies, they are all groups of individuals that do things in a collective way, seem in an intelligent way. The emergence of information technology favoured the appearance of new forms of collective intelligence. In their research, Web-enabled collective intelligence was investigated and they proposed a framework, based on the following questions: Who is performing the task? Why are they doing it? What is being accomplished? How is it being done? These questions fit in our ideas when dealing about collective intelligence in a learning approach, a learning community.

On the other hand, Klein (2007) underline that a collective intelligence is the result of a synergic and cumulative channelling of efforts built by various individuals that act in order to find out answers to challenges. This concept also fits in our ideas, about learning community. Klein's work proposes a collective intelligence system based on large-scale internet-enabled purpose, where members add value in contributions structured in an organized issues and arguments. This purpose is a quite different of web forums where individuals contribute in a global scale, where it can be found highly repetitive contents and highly variable quality, sometimes without focus. This is also a virtual community, but without a learning purpose in the form of a learning community.

What mostly leads a group of people to constitute a virtual community, whether a social or learning one, is their desire to be as close as possible to the ideal of an intelligent collectiveness. According to Lévy (2001a; 1999), we do not need to be intelligently guided by others, but rather to become mass intelligent, collectively. The term "collective" is not applied here to characterize only a link among "real" minds in connection, but also the communication among dead, alive and virtual minds that are still to come (Lévy, 1999; 1990). The collective intelligence would progressively allow the creation of forms of social organization and regulation that would lead to group thinking, the integration of intellectual forces, the multiplication of imagination and experience, and the real-time negotiation of practical solutions for those complex problems that afflict mankind. 


\section{Final Thoughts}

So, what is actually at stake? Is it just a new (or updated) learning method with its new tools, or can we go farther?

When we talk about education, we cannot rely on instruments alone. The big question is: "What do we want education for?" (Gardner, 2001). We agree with Howard Gardner, Leonardo Boff, Edgar Morin and Pierre Lévy, among others, when they say that the ultimate goal of education should be to broaden human comprehension. "To make buman consciousness aware of itself" (Lévy, 2001a).

No communication technique carries comprehension in itself. Comprehension can not be quantified; it only happens in the human consciousness. There, one finds man's true mission: "spreading comprehension among people as a condition and guarantee of mankind's solidarity and morals" (Morin, 1999).

According to Leonardo Boff's comments about Distance Learning (2004), "all knowledge has a humanitarian and social objective. It is about defending, expanding and elevating life to higher and more dignified levels." He says we should use new technologies and knowledge socialized by distance learning to create a state of consciousness adequate to the new "planetary phase of humanity", from which a human consciousness that is "more sensitive, caring, [and] fit for cooperation and solidarity" emerges.

Knowledge evolves constantly. It is impossible to stop people from having access to new discoveries, to deeper levels of knowledge. Improving human consciousness is fundamental, because one can make use of knowledge in a constructive, enlightening and creative way, as well as in a highly destructive, annihilating, deadly way. Gardner (2001) believes that the comprehension experiences that really matter are those we create as human beings in an imperfect world, which we can affect positively or negatively.

An excellent alternative to reach new levels of comprehension and consciousness is to connect humankind's multiple intelligences, going through a "collective intelligence" path. What we have at hand now is the chance to put this ideal into practice and create synergy around different knowledge, different views, and different people.

We are talking about possibilities that are part of the general virtualization movement humanity is going through. We can see escape routes, alternatives to expand consciousness and build a new society. This is not just about distance learning. It is about the possibility of broadening the reaches of education through an instrument that has the potential of a collective construction of knowledge, respecting the different types of intelligence of the actors involved. In Lévy's point of view (2001a), "true education and true learning fuse all disciplines in a global comprehension where learning about oneself is as important as knowing the world. The self-knowledge that can belp us understand who we are, all together, a consciousness illuminating the world." Finally, we can say we are not after solutions; we are after new problems that stake a claim for 'us', the 'plural', the 'common', and the 'collective'.

How prepared will be educators for this new scenario of learning? How learners will perform their creative capacities using multiple intelligences of Gardner in an open and distance learning space? How to support a collective construction of knowledge in a way to strengthen collective intelligence through open and distance learning? How should be structured multiple intelligence, open and distance learning in order to build a collaborative intelligence? Questions that we ask to go forward on this discussion. 


\section{References}

1. Akyol, Z.; Arbaugh, J.B.; Cleveland-Innes, M.; Garrison, D.R.; Ice, P.; Richardson, J.C. and Swan, K. (2009). A response to the review of the community of inquiry framework. In Journal of Distance Learning, 2(23), retrieved from: http://www.jofde.ca/index.php/jde/article/view/630/885

2. Anderson, T. and Elloumi, F. (eds) (2004). Theory and Practice of Online Learning. Athabasca Univerity.

3. Bayma, F. (2004). Educação a distância e educação corporativa. In F. Bayma (ed), Educação corporativa: desenvolvendo e gerenciando competências. São Paulo: Pearson Prentice Hall.

4. Boff, L. (2004). Desafios humanísticos e éticos da educação a distância. In F. Bayma (ed.), Educação corporativa: desenvolvendo e gerenciando competências. São Paulo: Pearson Prentice Hall.

5. Cardoso, V. and Bidarra, J. (2007). Open and distance learning: does IT (still) matter? In European Journal of Open, Distance and E-learning, retrieved from: http:/ / www.eurodl.org/index.php?article $=260$

6. Castells, M. (1998). End of millennium. Information age series. Vol 3. Wiley-Blackwell.

7. Castells, M. (2000). The rise of the network society: The information age: economy, society and culture. 2nd ed., Vol. 1. Wiley-Blackwell.

8. Deleuze, G. (1995). Difference \& repetition. New York: Columbia University Press.

9. Farquhar, L. (2013). The intersection of dialogue and low transactional distance: considerations for higher education. In European Journal of Open, Distance and E-learning, 16(2), retrieved from: http://www.eurodl.org/materials/contrib/2013/Farquhar.pdf

10. Gardner, H. (2001). Inteligência: um conceito reformulado. Rio de Janeiro: Objetiva.

11. Gardner, H. (2006). Changing minds: the art and science of changing our own and other people's minds. Harvard Business Review Series.

12. Holmberg, B. (1995). Theory and practice of distance education. 2nd ed., London: Routledge.

13. Holmberg, B. (2005). The evolution, principles and practices of distance education. Vol. 11. Oldenburg: Carl von Ossietzky Universität Oldenburg.

14. Keegan, D. (ed.) (1993). Theoretical principles of distance education. London: Routledge.

15. Klein, M. (2007). Achieving collective intelligence via large-scale on-line argumentation. Center for collective intelligence of MIT. Working paper n. 2007-001. Retrieved from http://papers.ssrn.com/sol3/papers.cfm?abstract_id=1040881

16. Lemos, A. (2002). Cibercultura: tecnologia e vida social na cultura contemporânea. Porto Alegre: Sulina.

17. Lévy, P. (1990). Les technologies de l'intelligence (sciences et societé). Paris : La Découverte.

18. Lévy, P. (1998). Qu'est-ce que le virtuel ? Paris : La Découverte.

19. Lévy, P. (1999). Collective intelligence: mankind's emerging world in cyberspace. Basic books.

20. Lévy, P. (2001a). Cyberculture. University of Minnesota Press.

21. Lévy, P. (2001b). A conexão planetária: o mercado, o ciberespaço, a consciência. São Paulo: Editora 34.

22. Malone, T.W.; Laubacher, R.; Dellarocas, C. (2010). Harnessing crowds: mapping the genome of collective intelligence. Center for collective intelligence of MIT. Working paper n. 4732-09. Retrieved from http://papers.ssrn.com/sol3/papers.cfm?abstract_id=1381502 
23. McMillan, D.W. and Chavis, D.M. (1986). Sense of community: a definition and theory. In Journal of Community Psychology, 14(Jan./1986), (pp. 6-23).

24. Morin, E. (1999). Les sept savoirs nécessaires à l'éducation du futur. UNESCO.

25. Nogueira, S.M. do N. (2003). Educação a distância e a formação dos educadores. In L. Alves \& C. Nova (eds.), Educação a distância: uma nova concepção de aprendizado e interatividade. São Paulo: Futura.

26. Nyíri, J.C. (1997). Open and distance learning in the information society. In European Journal of Open, Distance and E-learning, retrieved from: http://www.eurodl.org/index.php?article=3

27. Palloff, R.M. and Pratt, K. (2007). Building online learning communities: effective strategies for the virtual classroom. 2nd ed. Jossey-Bass.

28. Peters, O. (1992). Distance education: a revolutionary concept. In G. E. Ortner, K. Graff \& H. Wilmersdörfer (eds.), Distance education as two-way communication, Essays in honour of Börje Holmberg. Frankfurt: Peter Lang.

29. Peters, O. (2002). Distance education in transition: Development and issues. Vol. 5. Oldenburg: Carl von Ossietzky Universität Oldenburg.

30. Peters, O. (2004). A educação a distância em transição. São Leopoldo: Editora Unisinos.

31. Rourke, L. and Kanuka, H. (2009). Learning communities of inquiry: a review of the literature. In Journal of Distance Learning, 1(23), retrieved from: http://www.jofde.ca/index.php/jde/article/view/474/875

32. Rowntree, D. (1992). Exploring open and distance learning. Open and flexible learning series. Routledge.

33. Schlemmer, E. (2005). Metodologias para educação a distância no contexto da formação de comunidades virtuais de aprendizagem. In R.M. Barbosa (ed.), Ambientes virtuais de aprendizagem. Porto Alegre: Artmed.

34. UNESCO (2012). What is open and distance learning (ODL)? Retrieved from http://portal.unesco.org/education/en/ev.phpURL_ID=22329\&URL_DO=DO_TOPIC\&URL_SECTION=201.html

\section{Acknowledgments}

We would like to thanks to Acting Editor Dr. Ulrich Bernath, for his important suggestions that improved our essay. 